\title{
T-TEST ANALYSIS.
}

COMPARISON OF HPV-G REPORTER CELL SURVIVAL FOLLOWING TREATMENT WITH RAINBOW TROUT AND ZEBRAFISH EXPLANT MEDIA

\begin{tabular}{|c|c|c|c|c|c|c|}
\hline & \multicolumn{2}{|c|}{ GILLS (mean \pm SEM) } & \multicolumn{4}{|c|}{ SKIN (mean \pm SEM) } \\
\hline & $\begin{array}{l}\text { Trout } \\
(n=8)\end{array}$ & $\begin{array}{l}\text { Zebrafish } \\
(n=10)\end{array}$ & $\begin{array}{l}\text { T-test } \\
\text { Result }\end{array}$ & $\begin{array}{l}\text { Trout } \\
(n=8)\end{array}$ & $\begin{array}{l}\text { Zebrafish } \\
(n=15)\end{array}$ & $\begin{array}{l}\text { T-test } \\
\text { Result }\end{array}$ \\
\hline Sham X-ray & $99.1 \pm 9.6$ & $91.1 \pm 6.0$ & $\mathrm{HO}$ & $95.8 \pm 2.4$ & $84.4 \pm 4.8$ & $\mathrm{H} 1$ \\
\hline $\begin{array}{l}\text { Sham } \\
\text { waterborne }\end{array}$ & $78.9 \pm 8.9$ & $91.9 \pm 5.2$ & $\mathrm{HO}$ & $100.5 \pm 6.0$ & $83.8 \pm 4.9$ & $\mathrm{H} 1$ \\
\hline $\begin{array}{l}\text { Sham } \\
\text { partner fish }\end{array}$ & $92.8 \pm 6.7$ & $97.9 \pm 10.3$ & $\mathrm{HO}$ & $92.9 \pm 2.4$ & $85.7 \pm 8.3$ & Ho \\
\hline X-ray & $25.2 \pm 5.2$ & $54.1 \pm 6.3$ & $\mathrm{H} 1$ & $58.0 \pm 2.4$ & $45.8 \pm 5.2$ & $\mathrm{H} 1$ \\
\hline $\begin{array}{l}\text { Waterborne } \\
\text { B/S }\end{array}$ & $27.4 \pm 6.6$ & $39.8 \pm 8.8$ & $\mathrm{HO}$ & $44.4 \pm 7.6$ & $36.3 \pm 6.8$ & $\mathrm{HO}$ \\
\hline $\begin{array}{l}\text { Partner fish } \\
\text { B/S }\end{array}$ & $27.7 \pm 9.7$ & $52.9 \pm 4.8$ & $\mathrm{H} 1$ & $58.1 \pm 9.1$ & $43.7 \pm 5.1$ & $\mathrm{HO}$ \\
\hline
\end{tabular}

$\mathrm{H} 0$ = null hypothesis; no significant difference between trout and zebrafish mean.

$\mathrm{H} 1$ = alternative hypothesis; trout and zebrafish mean are significantly different $(\mathrm{P}<0.05)$

Supplementary table for on-line access showing the comparison between Rainbow trout data previously published (14) and the current Zebrafish data. 